METHODOLOGIC ISSUES

\title{
Drowning in Finland: "external cause" and "injury" codes
}

\author{
P Lunetta, A Penttilä, A Sajantila
}

Injury Prevention 2002;8:342-344

Background: The International Classification of Diseases (ICD) external codes (E codes) for drowning assist in determining the primary event leading to drowning, but do not alone allow the precise determination of the overall drowning rates.

Aims: To analyze the sensitivity of the ICD E codes for drowning. To describe the pattern and trend of drowning deaths that are classified with $\mathrm{E}$ codes other than for drowning.

Setting: Finland, 1969-2000.

Methods: Mortality files of Statistics Finland were searched electronically using the injury codes (I codes) and $\mathrm{E}$ codes for drowning. Cross analysis of I and $\mathrm{E}$ coded drownings was performed to

See end of article for authors' affiliations

.....................

Correspondence to: Dr Philippe Lunetta, PL 40 Kytösuontie 11 00300 Helsinki, Finland philippe.lunetta@helsinki.fi determine the rate and pattern of drowning cases classified with $E$ codes other than for drowning. Time trends were calculated using the Poisson regression model.

Results: Of 13705 drowning deaths, 644 (4.7\%) were not identified with the $\mathrm{E}$ codes for drowning. The great majority $(n=547,84.9 \%)$ of these cases were traffic accidents resulting in drowning. No significant time trends were found even after the introduction, in 1996, of the ICD 10th revision.

Conclusions: In Finland, underestimation of overall drowning rates using the $E$ code alone is less pronounced than in countries where similar studies have been performed. The relatively high rate of transport accidents resulting in drowning indicates a specific target for preventive countermeasures.
$\mathrm{F}$ or statistical purposes, drowning deaths can be classified under the International Classification of Diseases (ICD) injury (I code) and external cause of death (E code) codes. ${ }^{1}$ The World Health Organization basic tabulation list and the governmental agencies responsible for health statistics in several countries, however, classify drowning only with the ICD E coding frame. ${ }^{2}$ This single code tabulation may result in underestimation of drowning rates, since definite drowning cases may be classified only under E codes specifying the event leading the victim into the water, for example a motor traffic accident or fall, but not drowning itself. ${ }^{34}$

\section{METHODS}

Statistics Finland tabulates drowning with both I and E codes. ${ }^{56}$ Statistics Finland mortality files are based on certificates of cause of death issued by a physician, who for most unnatural deaths is the forensic pathologist performing the medicolegal autopsy. The proportion of drowning cases for which a medicolegal autopsy was performed during the study period was $92.5 \%$. This figure showed a constant upward time trend, rising to $98.2 \%$ during the last decade.

All drowning cases tabulated by Statistics Finland, 1969 through 1995, were selected for analysis (permission TK-531778-01) by the I and E codes for drowning in use during the study period (table 1). ${ }^{15-7}$ Cross analysis of I and E coded drownings was performed to determine the rate and pattern of drowning cases classified with $\mathrm{E}$ codes other than for drowning. Time trends were calculated by the $\chi^{2}$ test for trend and by the Poisson regression model (Egret software, 1996).

\section{RESULTS}

In Finland, during the period 1969 to 2000, of 131722 unnatural deaths $(84.2 / 100000 / y e a r, ~ M: F$ rate ratio 2.7$)$ 13705 were drownings (10.4\%; 8.8/100 000/year; M:F rate ratio 4.2 ) recorded with the I codes for drowning. Among these, $9710(70.9 \%)$ were accidental drownings, 2807 (20.5\%)
Table 1 ICD (8th, 9th, and 10th revisions) external injury codes ( $E$ code) and injury codes (I code) for drowning during the period 1969-2000

\begin{tabular}{llllll}
\hline & \multicolumn{2}{l}{ ICD-8 and ICD-9* } & & \multicolumn{2}{l}{ ICD-10 } \\
\cline { 2 - 3 } \cline { 5 - 6 } \cline { 5 - 6 } & I & E & & I & E \\
\hline Accidental drowning & 994.1 & E910 & & T75.1 & W65-74 \\
Boating related drowning & & E830, 832 & & V90, V92 \\
Suicide by drowning & E954 & & X71 \\
Homicide by drowning & E964 & & X92 \\
Undetermined drowning & E984 & & Y21 \\
\hline
\end{tabular}

*Finland used a modified version of the ICD-9 during the period 1987-95

suicides, $73(0.5 \%)$ homicides, and $1115(8.1 \%)$ deaths of undetermined intent (table 2).

Conversely, the search for drowning with the E codes revealed only 13061 drowning cases, that is, 644 (4.7\%) fewer than those found with the I codes (table 2). These 644 drownings were recorded with $\mathrm{E}$ codes other than for drowning.

\section{Accidental drowning}

Of 9710 accidental drownings, 9081 (93.5\%) were classified with an E code for drowning. The remaining 629 cases $(6.5 \%)$ had E codes other than for drowning, mostly for traffic accidents (table 3 ).

Transport accident related drownings* $(\mathrm{n}=547,0.3 / 100$ 000/ year, M:F 9.3) represented $5.6 \%$ of all accidental drownings $(\mathrm{n}=9710,6.2 / 100000 /$ year $)$ and $2.5 \%$ of all transport accidents $(n=22,148,14.2 / 100000 /$ year) occurring in the whole country, 1969-2000. More detailed information was available

Abbreviations: $\mathrm{Cl}$, confidence interval; $\mathrm{E}$ codes, external codes; I codes, injury codes; ICD, International Classification of Diseases 
Table 2 I and E coded drowning, by manner of death, during the period 1969-2000

\begin{tabular}{|c|c|c|c|c|}
\hline & \multicolumn{3}{|l|}{ I codes } & \multirow{2}{*}{$\frac{E \text { codes }}{\text { No }}$} \\
\hline & No & $\begin{array}{l}\text { No/100000/ } \\
\text { year }\end{array}$ & $\begin{array}{l}\text { Male:female } \\
\text { rate ratio }\end{array}$ & \\
\hline Accident & 9710 & 6.2 & 8.5 & 9081 \\
\hline Suicide & 2807 & 1.8 & 1.1 & 2797 \\
\hline Homicide & 73 & 0.05 & 1.4 & 73 \\
\hline Undetermined & 1115 & 0.7 & 3.5 & 1110 \\
\hline Total & 13705 & 8.8 & 4.2 & 13061 \\
\hline
\end{tabular}

Table 3 E coded accidental drowning ( $n=9710$ ) by external cause of death, in Finland (1969-2000)

\begin{tabular}{lr}
\hline & \multicolumn{1}{c}{ No $(\%)$} \\
\hline Drowning & $9081(93.5)$ \\
Transport accident & $547(5.6)$ \\
Water traffic & $23(0.2)$ \\
Late effects & $21(0.2)$ \\
Cataclysm & $8(0.1)$ \\
Aircraft accident & $8(0.1)$ \\
Other & $22(0.3)$ \\
\hline
\end{tabular}

on transport related drownings $(\mathrm{n}=86)$ during the period 1996-2000. Snowmobile accidents $(n=34)$, of which most occurred on ice, accounted for the majority of these deaths. Car accidents ( $\mathrm{n}=30,16$ without collision, 14 with collision), biking $(n=7)$, tractor $(n=5)$, motorbike $(n=4)$, and other miscellaneous cause $(n=3)$ accounted for the remaining cases. Alcohol data were available for 48 of the 69 victims aged 18-64 years: the blood alcohol concentration was more than $0.5 \%$ o in $70.8 \%$, more than $1.0 \%$ o in $56.2 \%$, and more than $2.0 \%$ in $22.9 \%$ of the cases.

\section{Trends}

The overall accidental drowning rate decreased significantly during the 32 year study period $(-2.74 \%$ /year, $95 \%$ confidence interval (CI) -2.95 to $-2.53, \mathrm{p}<0.001$, Poisson regression method). The accidental drowning coded with E codes other than for drowning $(-1.22 \% / y e a r$, $95 \%$ CI -2.06 to -0.37 , $\mathrm{p}=0.005$ ) also decreased significantly. However, the decrease in accidental drowning coded with $\mathrm{E}$ codes other than for drowning was less pronounced $(\mathrm{p}<0.001$, Cochrane-Armitage trend test).

Using the ICD 8th revision (1969-86) the proportion of drowning classified with an E code other than for drowning was 5.6\% (346/6152) of all drownings. This frequency grew during the Finnish classification (1987-95) and also after the introduction of the ICD 10th revision (1996-2000), respectively, to $7.7 \%(186 / 2401)$ and $8.3 \%(96 / 1156)$ of all cases (table 4).

The overall rates of transport accident decreased significantly $(-3.24 \%$ /year, $95 \%$ CI -3.38 to -3.09 , p $<0.001$, Poisson regression method), as did also the transport related drowning $(-1.42 \% / y e a r, 95 \%$ CI -2.35 to $-0.48, p=0.003)$, but the decrease in transport accident related drownings was less pronounced ( $\mathrm{p}<0.001$; Cochrane-Armitage trend test).

*The reported figures include all fatal transport accidents with the exclusion of air traffic, railways, and water transport fatal accidents. A detailed list if the codes used during the study period is available, on request, from the corresponding author (PL).
Table 4 Accidental drowning with $\mathrm{E}$ code other than for drowning in Finland (1969-2000), by classification mode*

\begin{tabular}{lllll}
\hline & ICD-8 & $\begin{array}{l}\text { Finnish } \\
\text { ICD-9 }\end{array}$ & ICD-10 & All \\
\hline $\begin{array}{llll}\text { Transport } \\
\text { accident }\end{array}$ & 298 & 168 & 81 & 547 \\
$\begin{array}{l}\text { Water traffic } \\
\text { Late effect }\end{array}$ & 20 & 13 & 8 & 23 \\
$\begin{array}{l}\text { Cataclysm } \\
\text { Aircraft }\end{array}$ & 7 & - & 1 & 21 \\
$\quad$ accident & 5 & - & 1 & 8 \\
Other & 14 & 4 & 1 & 8 \\
All $\dagger$ & $346(5.6 \%)$ & $187(7.7 \%)$ & $96(8.3 \%)$ & $629(6.5 \%)$ \\
\hline
\end{tabular}

* ICD 8th, 9th, and 10th revisions.

†The number in parenthesis indicates the percentage of all drowning

\section{Other unnatural causes of drowning}

Among 2807 suicides by drowning, only 10 (0.4\%) had E codes other than for drowning (six asphyxia, three late effect of injury, and one poisoning), while among 1115 drownings of undetermined intent, five $(0.4 \%)$ were those with E codes other than for drowning (one motor traffic accident, one late effect of accident, three other). Conversely, all 73 homicides by drowning were coded with the E codes specific for drowning (table 2).

\section{DISCUSSION}

Drowning is a multifactorial event that cannot be always described by a single external cause of death. For this reason, there are well defined exclusion rules that give precedence not to drowning but to the initiating event, that is, the cause that determines the victim's fall into water. ${ }^{4}$ The ICD 10th revision gives precedence to transportation and flood over drowning. ${ }^{1}$ In other cases, for example, accidental fall or suicide by jumping from a high place, no precise coding rules exist, and the certifying doctor has wider discretion in selecting codes.

Coding the underlying cause of death on the basis of the initiating event leading to death has a rationale for prevention but can hamper the determination of the real cause of death. In countries where statistical data are tabulated only with E code, there will be situations, for example, traffic accidents, in which-although there are no significant lesions caused by the car accident itself-there is no way possible to determine whether death occurred as a result of drowning. These cases will be missing from national statistics and the overall drowning rate underestimated. ${ }^{4}$

Previous studies have shown that reliance solely on E codes results in many drownings remaining unidentified. In Canada, a cross analysis of E and I codes revealed that $15 \%$ of all 1987 drownings $(n=952)$ were missed by using the E codes alone. ${ }^{3}$ Over a 15 year period in New Zealand (1977-92), a death certificate narrative search including the word "drowning" revealed $17.7 \%$ more drownings than those $(n=2310)$ recorded by E codes. ${ }^{4}$ In Australia, from 1992-97, a "flag system" for drowning allowed the identification of 5.4\% more cases than those $(n=2673)$ identified by the E codes. ${ }^{8}$ In Finland, the proportion of missing drownings by use of only the E code $(4.7 \%)$ is thus of the same magnitude as in the Australian study, but much lower than in Canada and New Zealand.

Most of the missed cases are transport accident related drownings. In Australia the proportion of transportation related drowning has been estimated to be $4.7 \%,{ }^{8}$ in Canada $7 \%,{ }^{3}$ and in New Zealand $11 \%{ }^{4}$ In Finland, the proportion $(5.6 \%)$ of transport related accidents was again similar to Australia's, but lower than in Canada and New Zealand. In other studies, the frequency of drowning coded as accidental 
fall or suicide by jumping from a high place is relatively high. For instance, in the New Zealand study, $7 \%$ of suicides leading to drowning were classified as suicide by jumping from a high place ${ }^{4}$ Finland had no drowning cases classified under falls or jumping from a high place, due to the fact that deaths in water caused, for instance, by falling or jumping from a bridge, are generally classified as drowning when the autopsy shows signs of drowning without severe injuries. During the study period, drownings tabulated with an E code other than for drowning and transport accident related drownings declined significantly, but less markedly than overall drowning cases, giving a relative increase in their proportion also after the introduction of the ICD 10th revision.

The accuracy of vital statistics can be improved in various ways. ${ }^{4}$ In Finland, where drowning rates are significantly higher than in the European Union and Nordic countries' average, ${ }^{9}$ Statistic Finland reports drowning-as does Canada ${ }^{3}$ - with both I and E codes. ${ }^{56}$ The utilization of multiple $\mathrm{E}$ codes is not allowed, but a I code is added beside the selected E code. Therefore the cross analysis of the I and $\mathrm{N}$ codes allows the identification of those cases in which drowning is the injury causing death, but the E code indicates a different event. In conclusion, the utilization of both the I and $\mathrm{E}$ codes increase accuracy in epidemiological studies on drowning and offer better compatibility for cross country comparison. The utilization of free narrative and flag systems can also improve the identification of drowning deaths. We believe, however, that accurate drowning estimates can be obtained only when police investigation and autopsy rates are high, since a number of deaths in water can be determined by a wide range of natural (for example, epilepsy) or unnatural causes other than drowning. In the cases of death in water caused by a natural disease actual coding rules appear inadequate. In Finland, the underestimation of overall drowning rates due to the use of the $\mathrm{E}$ axis alone is less pronounced than in some other countries where similar studies have been performed. The relatively high number of transport accidents leading to submersion and the association of such accidents with alcohol represent, however, selective targets for preventive actions.

\section{Authors' affiliations}

P Lunetta, A Penttilä, A Sajantila, Department of Forensic Medicine, University of Helsinki, Finland

\section{REFERENCES}

1 World Health Organization. International classification of diseases and related health problems. 10th revision. Geneva: WHO, 1992

2 Langley JD, Chalmers DJ. Coding the circumstances of injury: ICD-10 a step forward or backwards? Inj Prev 1999;5:247-53.

3 Bracker A. Drowning deaths: a cross-analysis of external and nature of injury codes. Health Reports 1989;1:225-8.

4 Smith G, Langley J. Drowning surveillance: how well do E codes identify submersion fatalities. Inj Prev 1998;4:135-9.

5 Lääkintöhallitus. Tautiluokitus, 1987. Valtion painatuskeskus, Helsinki, 1986.

6 Stakes. Finnish version of the international classification of diseases and related health problems. 10th Revision, vol 1. Helsinki, 1999.

7 World Health Organization. International classification of diseases. 8th Revision, vol 1. Geneva: WHO, 1967.

8 Mackie IJ. Patterns of drowning in Australia, 1992-1997. Med J Aust 1999;171:587-90.

9 Lunetta P, Penttilä A, Sarna S. Water traffic accidents, drowning and alcohol in Finland, 1969-1995. Int J Epidemiol 1998;27:1038-43.

\section{BOARD MEMBER BIOGRAPHY}

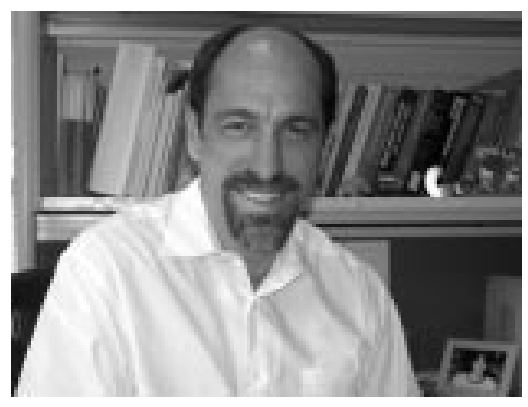

\section{James A Mercy}

James A Mercy is the Associate Director for Science of the Division of Violence Prevention in the National Center for Injury Prevention and Control of the Centers for Disease Control and Prevention (CDC). He received his $\mathrm{PhD}$ in sociology from Emory University in Atlanta. After his graduation, Mercy began working at CDC as an Epidemic Intelligence Service Officer in a newly formed activity to examine violence as a public health problem. Over the two decades since he joined CDC, Mercy has conducted and overseen numerous studies of the epidemiology of youth suicide, family violence, homicide, and firearm injuries. His publications include "Fatal violence among spouses in the United States, 1976-1985" in the American Journal of Public Health; "Firearm injuries: a call for science" in the New England Journal of Medicine; "Public health policy for preventing violence" in Health Affairs; and "Is suicide contagious? A study of the relation between exposure to the suicidal behavior of others and nearly lethal suicide attempts" in the American Journal of Epidemiology. He is currently a coeditor of the World Report on Violence and Health to be released later this year by the World Health Organization. 